\title{
Ureterostomias cutânea e colônica em suínos: avaliação da exequibilidade das técnicas
}

\author{
[Cutaneous ureterostomies in pigs: technical feasibility assessment] \\ T.D. Prado ${ }^{1}$, R.G. Ribeiro ${ }^{1}$, T.L.E. Treichel ${ }^{1}$, A.B. De Nardi ${ }^{2}$ \\ ${ }^{1}$ Universidade de Rio Verde - Rio Verde, GO \\ ${ }^{2}$ Universidade Estadual Paulista - Jaboticabal, SP
}

T.D. Prado1
http://orcid.org/0000-0001-6273-8885
R.G. Ribeiro1
http://orcid.org/0000-0003-0755-4121
T.L.E. Treichel1
http://orcid.org/0000-0002-0192-055x
A.B. De Nardi2
http://orcid.org/0000-0001-6463-2144

RESUMO

O aumento da expectativa de vida dos animais de companhia favorece a ocorrência de casos de câncer, como o de bexiga. O objetivo da presente pesquisa foi avaliar a exequibilidade da técnica de ureterostomia cutânea em suínos após a realização da cistectomia total, quando comparada à técnica de ureterostomia colônica, assim como detectar e caracterizar possíveis complicações transoperatórias. Foram utilizados 20 animais, distribuídos em dois grupos. Todos foram submetidos à cistectomia radical e, em seguida, à ureterostomia cutânea ou colônica. A exequibilidade das técnicas foi avaliada. Observouse o tamanho da incisão, o tempo de diérese, de realização da derivação urinária e o tempo de síntese, estimou-se a perda sanguínea e o grau de dificuldade na realização dos procedimentos de preparo dos ureteres, o preparo do sítio de ureteroanastomose e a realização da ureteroanastomose em si. Os resultados indicam que a ureterostomia cutânea apresentou maior eficiência quando comparada à colônica nos quesitos perda de sangue, tamanho da incisão realizada e facilidade de realização da anastomose. Já a ureterocolostomia apresentou melhor resultado referente à execução do preparo ureteral. Assim, concluiuse que ambas as técnicas podem ser indicadas como derivações urinárias viáveis e que a escolha dependerá de fatores intrínsecos ao cirurgião e ao paciente.

Palavras-chave: porco, anastomose, bexiga, neoplasia, ureter

\begin{abstract}
Increased life expectancy of pets favors the occurrence of cancer, such as the urinary bladder ones. The aim of this study was to evaluate the feasibility of cutaneous ureterostomy technique in pigs after the total cystectomy compared to the technique of colonic ureterostomy, as well as detect and characterize possible intraoperative complications. For that, 20 pigs were used, divided into two groups. All patients underwent radical cystectomy and then the cutaneous or colonic ureterostomies. The technical feasibility was assessed during the procedures. The procedures compared were: the incision size, dieresis time, realization of urinary diversion and the synthesis time. Also, the estimated blood loss and the degree of difficulty in performing the preparation procedures of the ureters, ureteroanastomose site preparation and ureteroanastomose itself were compared. The results indicate that performing cutaneous ureterostomy was better than the colonic ureterostomy in relation to blood loss, incision size, and anastomosis performance. In contrast, ureterocolonostomy showed better results on the implementation of ureteral preparation. Thus, it was concluded that both techniques can be indicated as viable urinary diversions and the choice will depend on factors intrinsic to the surgeon and the patient.
\end{abstract}

Keywords: pig, anastomosis, bladder, neoplasm, ureter

\section{INTRODUÇÃO}

Entre os diversos órgãos do sistema urinário dos animais de companhia, a bexiga é o mais acometido pelas neoplasias. Os tumores vesicais correspondem a cerca de $2 \%$ do total de casos de neoplasias na espécie canina, e na espécie felina são raros (Carvalho e Brum, 2009). As raças mais predispostas são Airedale, Scottish Terrier, Shetland, Sheepdog, Collie e Beagle (Pazzini et al., 2005).

Recebido em 23 de novembro de 2016

Aceito em 5 de setembro de 2018

E-mail: talesprado@yahoo.com.br 
Os pacientes que apresentam câncer invasivo na bexiga em estágio avançado são usualmente tratados com cirurgia radical, radioterapia, quimioterapia ou mesmo com a combinação de duas ou mais dessas modalidades de tratamento (Srouge et al., 2003). A cistectomia radical é considerada como o tratamento "padrão ouro" para os tumores vesicais que invadem a musculatura própria da bexiga (Ortiz, 2006).

A cistectomia desencadeia a necessidade de uma derivação urinária. As principais técnicas geralmente consideradas são a do conduto ileal ou a própria substituição da bexiga. Entretanto, essas derivações mostram uma alta taxa de complicações. A ureterostomia cutânea parece ser uma alternativa interessante e constitui uma intervenção simples, reprodutível, com taxa de mortalidade razoável. A morbidade, o início e a duração da hospitalização são reduzidos pela ausência de utilização intestinal. Em seres humanos, essa técnica é bem aceita pelos pacientes, que a consideram como satisfatória para a qualidade de vida (Doerfler et al., 2012).

Os riscos inerentes à ureterostomia cutânea, contudo, estão associados principalmente à estenose. Se a cirurgia for bem-sucedida, sem a necessidade de implantação de tubo no ureter, as complicações tardias também são reduzidas e o procedimento parece ser tão bom quanto outros, como o conduto ileal (Hirokawa et al., 1989; Kim et al., 2005).

O objetivo para tratamento do paciente que sofrerá desvio urinário deve ser determinar o método mais seguro para o controle do câncer, que cause menores complicações, tanto em curto como em longo prazo, e que forneça melhor qualidade de vida a ele (Hautmann et al., 2007). Também deve oferecer proteção das vias superiores e, se possível, a restauração funcional e anatômica do sistema excretor, o mais próximo possível ao estado pré-operatório natural (Rodriguez et al., 2011).

Sabe-se que o aumento da expectativa de vida dos pequenos animais de companhia favorece a ocorrência de casos de câncer, como o de bexiga. Dessa forma, faz-se necessário dispor de alternativas que minimizem o sofrimento $\mathrm{e}$ melhorem a qualidade de vida desses pacientes após a remoção cirúrgica da bexiga. Contudo, apesar de muito bem descritas pela tradicional medicina humana, as técnicas instituídas para a medicina veterinária ainda demandam mais pesquisas, para que possam ser denominadas como padrão. Usualmente, no meio veterinário, a técnica de ureterostomia colônica é realizada nos pacientes submetidos à cistectomia radical, no entanto existem técnicas alternativas e menos agressivas que podem ser realizadas no intuito de minimizar as complicações que possam ocorrer com essa técnica.

O objetivo da presente pesquisa foi avaliar a exequibilidade da técnica deureterostomia cutânea em suínos após a realização da cistectomia total, quando comparada à técnica de ureterostomia colônica, assim como detectar e caracterizar possíveis complicações transoperatórias. Apesar de ter sido desenvolvida em animais na espécie suína, o modelo de cirurgia foi pensado e proposto para animais da espécie canina, portadores de neoplasias graves da bexiga e que necessitem de uma derivação urinária segura e facilmente exequível póscistectomia radical.

\section{MATERIAL E MÉTODOS}

O presente trabalho foi aprovado pelo Comitê de Ética no Uso de Animais da Universidade de Rio Verde, sob o protocolo $\mathrm{n}^{\circ}$ 04-13. Foram utilizados 20 suínos fêmeas, de raça mestiça (Large White x Landrace), oriundos de granjas da microrregião de Rio Verde, GO, desverminados, com aproximadamente 50 dias de idade e com peso aproximado de $15 \mathrm{~kg}$.

Foram formados dois grupos com 10 animais cada, por delineamento inteiramente ao acaso. Todos os animais foram submetidos ao procedimento de cistectomia radical, indicado para animais portadores de neoplasias invasivas da bexiga (Ortiz, 2006). Após a cistectomia, os animais foram submetidos a duas diferentes derivações urinárias: no grupo I (GI), foi realizada a técnica de ureterostomia cutânea, com a implantação do ureter próximo à linha média do abdome, em região retroumbilical; no grupo II (GII), foi realizada a ureterostomia colônica, com a implantação do ureter na porção distal do cólon.

Nos animais do GI, antes da cirurgia, dois estomas foram delineados lateralmente à linha média, caudalmente ao quarto par de glândulas 
mamárias de cada lado, para posterior implantação dos ureteres. Finalizada a cistectomia, os ureteres foram cautelosamente desprendidos por dissecção romba e mobilizados até próximo da parede abdominal. Durante a dissecção, foi imprescindível a manutenção da viabilidade da vascularização dos ureteres, por meio da manipulação cautelosa da estrutura. Os ureteres foram dissecados até a região próxima ao polo caudal do rim. Ainda por dissecção romba, um túnel extraperitoneal foi criado para cada ureter, com comunicação para o local onde o estoma foi criado.

Os ureteres foram mobilizados o suficiente para chegarem a cerca de dois centímetros acima da pele, sem tensão. Em seguida, foram suturados na pele com fio monofilamentar inabsorvível sintético 5-0. Procedeu-se, na sequência, à celiorrafia da linha média com fio monofilamentar inabsorvível sintético 0 , em padrão Sultan, do subcutâneo com fio absorvível multifilamentar sintético, em padrão intradérmico, e da pele com fio monofilamentar inabsorvível sintético 2-0,em padrão Wolff. Uma sonda foi, então, posicionada em cada estoma criado, fixada à pele com fio de náilon e mantida aberta para permitir o gotejamento da urina. Os animais receberam curativos locais e fixação de material absorvente com esparadrapo à pele, de forma que a urina fosse absorvida à medida que era eliminada e os estomas não ficassem expostos (Fig. 1).

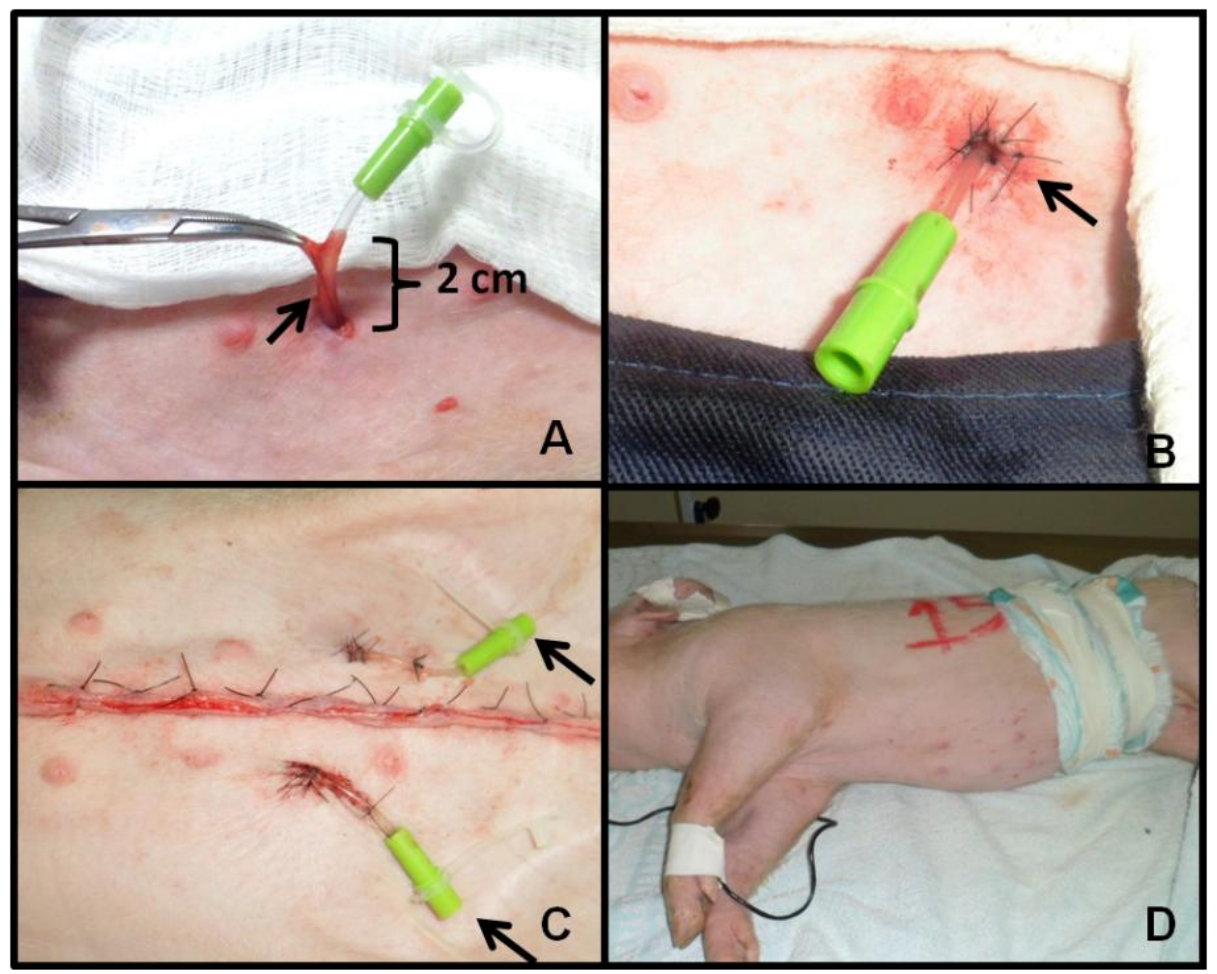

Figura1. Ureterostomia cutânea em suíno. A - Ureter (seta) exteriorizado através do túnel construído na parede abdominal. Aproximadamente dois centímetros dos ureteres foram posicionados fora da cavidade, sem que houvesse tensão. B - Ureter (seta) suturado à pele e manutenção da sonda uretral. C Ureterostomia bilateral realizada e sondas fixadas (setas) à pele. D - Curativo posicionado.

No GII, após a cistectomia radical, os ureteres foram cautelosamente dissecados, sem a necessidade de dissecção até próximo ao polo caudal do rim, e conduzidos para próximo ao cólon. A técnica de ureterostomia colônica adotada foi uma modificação da técnica proposta por Fossum (2014), de forma que não foi instituído o retalho seromuscular proposto pela autora, e sim procedeu-se à implantação ureteral direta em uma incisão feita por todas as camadas intestinais. Duas pequenas incisões laterais no cólon foram realizadas, em níveis diferentes. Os ureteres foram implantados e fixados por meio de pontos simples isolados com fio absorvível 
sintético monofilamentar 5-0 (Fig. 2). Em seguida à implantação dos ureteres, foi realizado o teste de oclusão por meio da distensão da alça envolvida com solução de cloreto de sódio a $0,9 \%$. Após a constatação da ausência de vazamento nas anastomoses, a omentopexia foi realizada. Por fim, foi realizada a celiorrafia de forma semelhante ao grupo da ureterostomia cutânea.

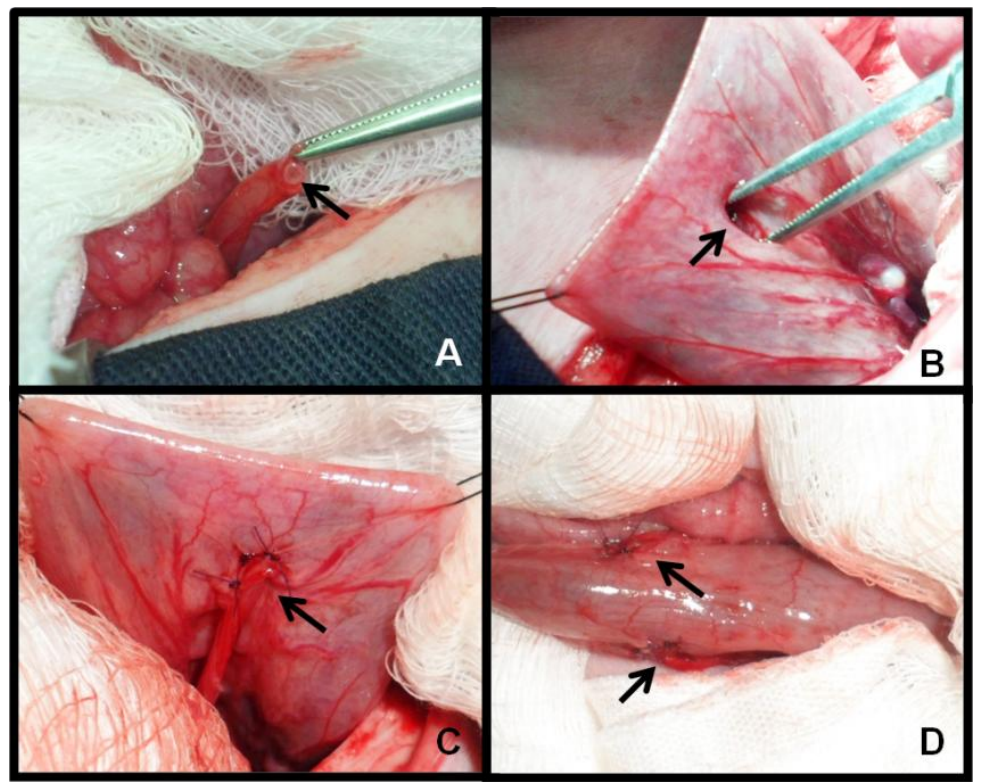

Figura 2. Ureterostomia colônica em suíno. A - Ureter já dissecado e pronto para a implantação. Observar que a pinça já foi retirada, e o segmento que foi comprimido por ela removido (seta). B - Incisão realizada no cólon para a implantação do ureter (seta). C - Ureter parcialmente suturado ao cólon (seta). D - Aspecto final da ureterostomia colônica.

As avaliações da exequibilidade da técnica fundamentaram-se no tempo de realização da cirurgia, na perda sanguínea gerada, no tamanho da incisão cirúrgica e no nível de dificuldade observado pelo cirurgião.

Durante os procedimentos, foram cronometrados os tempos de diérese (acesso à cavidade e identificação das estruturas), da derivação urinária (incluindo todo o procedimento $\mathrm{e}$ as manobras para hemostasia, se necessárias) e de síntese (desde o início da celiorrafia até o último ponto de pele), para que, ao final, fosse possível estimar as etapas do procedimento realizado, assim como o tempo total do procedimento.

A perda sanguínea foi estimada por pesagem das compressas e gazes utilizadas durante o procedimento. Após a celiotomia, duas compressas secas e não pesadas foram utilizadas para secar a cavidade e eliminar possíveis excessos de líquidos presentes. Em seguida, todas as gazes e as compressas utilizadas eram imediatamente pesadas. Uma vez que elas haviam sido pesadas anteriormente, era possível estimar a diferença de peso e, por conseguinte, a quantidade de sangue perdido. Ao final do procedimento, realizou-se a somatória dos valores de peso observados durante a cirurgia para a determinação da quantidade total de sangue perdido, em gramas. Outra forma de monitorar a perda sanguínea foi a realização de hemograma imediatamente antes e após os procedimentos cirúrgicos, para observação do volume globular.O tamanho da incisão cutânea foi medido com régua logo após a celiorrafia.

Com base na experiência do cirurgião, que leva em consideração a residência médico-veterinária em clínica e cirurgia de pequenos animais, o mestrado em cirurgia veterinária e a atuação como professor de cirurgia de pequenos animais durante quatro anos, que totalizam oito anos de experiência na área, classificou-se cada procedimento com graus de dificuldade, que variaram da seguinte forma: 1 (fácil), 2 (médio) e 
3 (difícil). A classificação foi realizada imediatamente após o final do procedimento. As manobras avaliadas foram: preparo dos ureteres, preparo do sítio receptor da derivação e, por fim, realização da derivação.

Os resultados foram submetidos previamente à determinação da normalidade. Para a determinação dos tempos cirúrgicos, do tamanho da incisão e da quantidade de sangue perdido, foi utilizada a análise de variância (ANOVA), complementada pelo teste t. Para as avaliações dos graus de dificuldade dos procedimentos, utilizou-se o teste de Mann-Whitney. Os valores de $\mathrm{P}<0,05$ foram considerados significantes, e o programa estatístico utilizado foi o BioEstat 5.4.

\section{RESULTADOS E DISCUSSÃO}

Durante o estudo, realizaram-se 20 cirurgias e todas ocorreram sem intercorrências importantes, visto que não foi registrado óbito de nenhum animal durante a execução dos procedimentos planejados.

Os tempos de diérese da parede abdominal, da derivação ureteral, de síntese da parede abdominal e o tempo total de cirurgia foram cronometrados, e suas médias, em minutos, encontram-se na Tab. 1.

Tabela 1. Médias dos tempos de diérese da parede abdominal, da derivação ureteral, de síntese da parede abdominal e tempo total de cirurgia de suínos submetidos às derivações ureterais cutânea e colônica

\begin{tabular}{lccccc} 
& \multicolumn{4}{c}{ Ureterostomia cutânea } & \multicolumn{2}{c}{ Ureterostomiacolônica } & \\
Procedimentos & $\begin{array}{c}\text { Tempo } \\
\text { (min) }\end{array}$ & SD & $\begin{array}{c}\text { Tempo } \\
\text { (min) }\end{array}$ & SD & $\mathrm{p}$ \\
\hline $\begin{array}{l}\text { Diérese da parede } \\
\text { abdominal }\end{array}$ & 1,82 & $\pm 0,72$ & 2,20 & $\pm 1,12$ & 0,38 \\
$\begin{array}{l}\text { Derivação ureteral } \\
\text { Síntese da parede }\end{array}$ & 55,48 & $\pm 7,56$ & 59,67 & $\pm 14,0$ & 0,41 \\
abdominal & 15,98 & $\pm 3,54$ & 16,84 & $\pm 1,96$ & 0,51 \\
Tempo total de cirurgia & 73,28 & $\pm 10,93$ & 78,71 & $\pm 15,16$ & 0,37 \\
\hline
\end{tabular}

Análise de variância complementada pelo teste t $(\mathrm{P}>0,05)$.

Observou-se que não houve diferença significativa entre as médias do tempo de diérese da parede abdominal, da derivação ureteral, de síntese da parede abdominal e do tempo total do procedimento cirúrgico entre os grupos analisados. Contudo, o tempo médio de realização da ureterostomia cutânea $(73,28$ minutos) foi inferior ao tempo médio de realização das ureterostomiacolônica $(78,71$ minutos).

Diversos pesquisadores já utilizaram a quantificação dos tempos cirúrgicos como forma de comparação entre técnicas empregadas. Malm et al. (2004) compararam os tempos cirúrgicos de ovário-histerectomias por laparoscopia e por laparotomia mediana em cadelas. Coe et al. (2006) e Prado et al. (2015a) também demonstram a importância da verificação do tempo gasto para a realização de procedimentos cirúrgicos envolvendo felinos;eles averiguaram os tempos, em minutos, das manobras cirúrgicas utilizadas para realização de ováriohisterectomias. Todos esses estudos indicaram que mudanças na abordagem, ou mesmo na técnica cirúrgica adotada, podem influenciar a cirurgia, diminuindo ou aumentando o tempo total dos procedimentos.

Há unanimidade entre os pesquisadores citados (Malm et al., 2004; Coe et al., 2006; Prado et al., 2015a) quanto à importância da diminuição do tempo cirúrgico para os pacientes, principalmente os críticos. Assim, a determinação dos tempos cirúrgicos realizada em suínos que foram submetidos a duas derivações urinárias fez-se fundamental na comparação das técnicas, mesmo que os resultados não tenham demonstrado diferenças significativas entre os grupos.

Convém lembrar que o tempo dos procedimentos cirúrgicos está intimamente relacionado ao treinamento e à habilidade da equipe cirúrgica, fato esse que pode minimizar mais ainda o tempo cirúrgico (Costa et al., 2009). 
O tamanho médio das incisões realizadas em suínos submetidos à ureterostomia colônica foi $(17,25 \pm 1,31 \mathrm{~cm})$, claramente, maior que o tamanho médio das incisões realizadas para a ureterostomia cutânea $(15,23 \pm 4,58 \mathrm{~cm})$, com diferenças significativas entre os grupos de $(\mathrm{P}=0,006)$

Sabe-se que o tamanho da incisão pode influenciar sobremaneira a recuperação do paciente, e os resultados observados justificam a supremacia da técnica de ureterostomia cutânea sobre a colônica no que se refere ao tamanho da incisão. Em medicina humana, esse tipo de avaliação vem sendo utilizado há muito tempo, como nos estudos cardiológicos realizados por Dias et al. (1999) e Sampaio et al. (2005). Já em medicina veterinária, alguns autores, como Santos (2011) e Prado et al. (2015a), justificam a utilização dessas avaliações com seus resultados.

A Tab. 2 apresenta informações relativas à perda de sangue durante os procedimentos cirúrgicos.

Os animais submetidos à derivação ureteral cutânea perderam menor quantidade de sangue $(\mathrm{P}=0,001)$ que os submetidos à derivação colônica. Já os animais submetidos à ureterostomia colônica tiveram menor decréscimo percentual do hematócrito que os animais submetidos à ureterostomia cutânea, com diferenças significativas entre os grupos $(\mathrm{P}=0,0304)$.

Tabela 2. Médias da quantidade de sangue perdida, em gramas, e da redução no valor do hematócrito, em porcentagem, de suínos submetidos às derivações ureterais cutânea e colônica

\begin{tabular}{|c|c|c|c|c|c|}
\hline \multirow[b]{2}{*}{ Parâmetros } & \multicolumn{2}{|c|}{ GI } & \multicolumn{2}{|c|}{ GII } & \multirow[b]{2}{*}{$\mathrm{p}$} \\
\hline & Média & SD & Média & SD & \\
\hline Hemorragia (g) & $39,87^{\mathrm{B}}$ & $\pm 11,39$ & $65,30^{\mathrm{A}}$ & $\pm 17,32$ & 0,001 \\
\hline $\begin{array}{c}\text { Redução do hematócrito } \\
(\%)\end{array}$ & $3,8^{\mathrm{A}}$ & $\pm 2,29$ & $1,9^{\mathrm{B}}$ & $\pm 1,44$ & 0,0304 \\
\hline
\end{tabular}

Letras distintas na linha diferem entre si após a realização do teste $\mathrm{t}$.

* As médias marcadas indicam que, mediante aplicação do teste $t$, houve diferença significativa entre os grupos, com $\mathrm{P}<0,05$.

Essas constatações podem parecer controversas, uma vez que o grupo que apresentou menor quantidade de hemorragia (GI) mostrou maior decréscimo do hematócrito $(3,8 \pm 2,29 \%)$, enquanto o grupo que apresentou maior perda sanguínea oriunda do procedimento cirúrgico (GII) demonstrou menor redução do hematócrito $(1,9 \pm 1,44 \%)$. A variabilidade exibida entre indivíduos pode constituir forma de entendimento dessa dinâmica. Campbell(2015) infere que diversos fatores podem influenciar o hemograma, entre eles idade, condições ambientais, dieta, gênero e estado reprodutivo, fatores esses muito variáveis entre as espécies e mesmo dentro da própria espécie.

Outros fatores também relacionados às alterações no hemograma são deficiência de eritropoetina, doença renal crônica, deficiência de ferro, deficiência de ácido fólico e vitamina B12,perdas sanguíneas, hemólise e inflamação (Abensur, 2004), além da administração de alguns tipos de fármacos,como os benzodiazepínicos (Cortopassi e Fantoni, 2002). Entretanto, como os animais utilizados no experimento apresentavam-se saudáveis, à exceção das hemorragias, todos esses possíveis fatores descritos podem ser desconsiderados como fontes de alterações.

A avaliação do grau de dificuldade na execução dos procedimentos encontra-se expressa na Tab. 3. Para tal, levou-se em consideração a experiência do cirurgião, que classificou cada procedimento em escores (1- fácil, 2 - médio e 3 - difícil). As manobras avaliadas foram: preparo dos ureteres, preparo do sítio receptor da anastomose e, por fim, realização da anastomose. Os resultados estão descritos na Tab. 3. 
Tabela 3. Medianas referentes aos graus de dificuldade para realização dos procedimentos de preparo dos ureteres, preparo do sítio receptor da anastomose e anastomose, realizados durante derivações ureterais cutâneas e colônicas em suínos

\begin{tabular}{lccc}
\multicolumn{1}{c}{ Grupos } & Ureterostomia cutânea & Ureterostomiacolônica & \\
& Mediana & Mediana & $\mathrm{P}$ \\
\hline Preparo dos ureteres & $2^{\mathrm{A}}$ & $1,5^{\mathrm{B}}$ & 0,029 \\
Preparo dos sítios & $1^{\mathrm{NS}}$ & $1^{\mathrm{NS}}$ & 0,5 \\
Anastomose & $1,5^{\mathrm{B}}$ & $2^{\mathrm{A}}$ & 0,027 \\
\hline
\end{tabular}

*As médias marcadas indicam que, mediante aplicação do teste de Mann-Whitney, houve diferença significativa entre os grupos, com $\mathrm{P}<0,05$. Letras distintas nas linhas indicam diferenças significativas entre os grupos. NS= não significativa.

O preparo dos ureteres de animais submetidos à ureterostomia cutânea mostrou-se mais complicado que o preparo dos ureteres que foram submetidos à ureterostomiacolônica. Tal fato pode ser explicado devido à necessidade de dissecção mais prolongada dos ureteres, chegando ao polo distal do rim ipsilateral.

Autores como Nogueira et al. (2013) e Fossum (2014) descrevem as técnicas de abordagem dos ureteres, contudo não abordam a necessidade de liberação total do peritônio até o polo caudal do rim. Tal necessidade foi observada na prática, enquanto o experimento foi delineado.

Não houve diferença estatística quanto à dificuldade no preparo do sítio receptor dos ureteres, tanto no preparo do túnel transabdominal quanto no preparo do sítio receptor no cólon, que foram procedimentos de fácil realização.

A criação dos estomas responsáveis pela drenagem da urina deu-se primeiramente pela realização de túneis transabdominais. Estudos realizados em humanos (Yoshimura et al., 2001; Nogueira et al., 2013) e também em animais(Prado et al., 2015b) mostram que esses túneis podem ser realizados de forma fácil e rápida, exatamente como observado nos animais do experimento.

Autores consagrados, como Slatter (2003) e Fossum (2014), inferem que a incisão no intestino deve contemplar a realização de retalho seromuscular antes de adentrar a mucosa do órgão. A técnica modificada utilizada para a fixação do ureter nocólon não foi realizada mediante levantamento do retalho intestinal, devido à dificuldade encontrada em virtude da espessura das camadas do órgão; contudo, mostrou-se mais facilmente exequível que a técnica tradicionalmente realizada.

Observou-se, com a experiência adquirida durante o experimento, que as derivações intestinais requerem muitos cuidados e são mais difíceis de serem executadas, confirmado pela diferença significativa $(\mathrm{P}=0,027)$ no grau de dificuldade entre a realização da anastomose cutânea e da anastomose colônica.

\section{CONCLUSÕES}

Conclui-se que ambas as técnicas são exequíveis, sem prejuízos imediatos aos pacientes. No entanto, a técnica de ureterostomia cutânea demonstrou-se superior com relação à perda de sangue, ao tamanho da incisão abdominal realizada e à facilidade de execução da anastomose cutânea, quando comparada à técnica de ureterostomiacolônica. Assim, acredita-se que ambas as técnicas podem ser indicadas como derivações urinárias viáveis e que a escolha dependerá de fatores intrínsecos ao cirurgião e ao paciente.

\section{AGRADECIMENTOS}

À Fapeg e à Capes, pela bolsa de doutorado concedida. 


\section{REFERÊNCIAS}

ABENSUR, H. Anemia da doença renal crônica. $J$. Bras. Nefrol.,v.26, p.26-28, 2004

CAMPBELL, T.W. Hematologia dos mamíferos / animais de laboratório e espécies variadas. In _: THRALL, M.A.; WEUSER, G.; ALLISON, R.W. et al. Hematologia e bioquímica clínica veterinária. 2.ed. São Paulo: Roca, 2015. p.194-204.

CARVALHO, M.B.; BRUM, A.M. Neoplasias do sistema urinário. In: DALECK, C.R.; NARDI, A.B.; RODASKI, S. Oncologia em cães e gatos. São Paulo: Roca, 2009. p.386-398.

COE, R.J.; GRINT, N.J.; TIVERS, M.S. et al. Comparison of flank and midline approaches to the ovariohysterectomy of cats. Vet. Rec., v.13, p.464-467, 2006.

CORTOPASSI, S.R.G; FANTONI, A.T. Medicação pré anestésica. In: São Paulo: Roca, 2002. p.151-158.

COSTA, J.M.; TEIXEIRA, E.M.; FERREIRA FILHO, E.M. et al. Braçadeiras de náilon para hemostasia preventiva na ovário-histerectomia em gatas.Rev. Bras. Saúde Prod. Anim.,v.10, p.615-624, 2009.

DIAS, R.R.; SOBRAL, M.L.P.; AVELAR JÚNIOR, S.F. et al. Cirurgia da valva aórtica: estudo prospectivo e randomizado da miniesternotomia versus cirurgia convencional. Rev. Bras. Cir. Cardiovasc., v.14, p.98-104,1999.

DOERFLER, A.; CHAHWAN, C.; GAL, S. et al. Cutaneous ureterostomy: back to the future?J. Urol., v.187, p.493, 2012.

FOSSUM, T. W. Cirurgia da bexiga e da uretra. In: Cirurgia de pequenos animais. 2.ed. São Paulo: Roca, 2014. p.735-779.

HAUTMANN, R.E.; ABOL-ENEIN, H.; HAFEZ, K. et al. Urinary diversion. Urology, v.69, p.17-49, 2007.

HIROKAWA, M.; IWASAKI, A.; YAMAZAKI, A. et al. Improved technique of tubeless cutaneous ureterostomy and results of permanent urinary diversion. Eur. Urol., v.16, p.125-132, 1989.

KIM, C.J.; WAKABAYASHI, Y.; SAKANO, Y. et al. Simple technique for improving tubeless cutaneous ureterostomy. Urology, v.65, p.1221-1225, 2005.
MALM, C.; SAVASSI-ROCHA, P.R.; GHELLER, V.A. et al. Ovário-histerectomia: estudo experimental comparativo entre as abordagens laparoscópicas e aberta na espécie canina. Intra-operatório-I. Arq. Bras.Med. Vet. Zootec., v.56, p.457-466, 2004.

NOGUEIRA, L.; REIS, R.B.; MACHADO, R.D.; MACHADO, M.T. et al. Ureterostomia cutânea como opção de derivação urinária em pacientes em condições clínicas após cistectomia radical. Acta Cir. Bras., v.28, p.43-47, 2013.

ORTIZ, V. Cistectomia radical no idoso. Rev. Bras. Med., n.3, p.82-83, 2006.

PAZZINI, J.C.; COSTA, C.M.B.; COSTA, J.L.O. et al. Cistectomia parcial no tratamento de carcinoma de bexiga em cão. Rev. Cient. Elet. Med. Vet., n.4, p.1-4, 2005.

PRADO, T.D.; BARBOZA, S.; MONI, A.F. et al. nylon clamps and mononylon for ovariohysterectomy in cats. Encic. Bios., v.11, p.1397-1411, 2015a

PRADO, T.D.; RIBEIRO, R.G.; PEREIRA, C.C.H. et al. Ureterostomia cutânea em cão: Relato de caso. Encicl. Biosf., v.11, p. 2714-2722, 2015b

RODRÍGUEZ, A.R.; LOCKHART, A.; KING, J. et al. Cutaneous ureterostomy technique for adults and effects of ureteral stenting: an alternative to the ileal conduit. J. Urol., v.186, p.1939-1943, 2011.

SAMPAIO, L.C.N.; CARVALHO, J.L.; ALVES, M.A.V. et al, Estudo comparativo entre a miniesternotomia em "L" invertido e esternotomia longitudinal total na correção cirúrgica da comunicação interatrial. Rev. Bras. Cir. Cardiol., v.20, p.46-51, 2005.

SANTOS, C.A.S.F. Estudo comparativo $d a$ ovariohisterectomia felina com incisão no flanco e na linha média. 2011. Dissertação (Mestrado) Faculdade de Medicina Veterinária, Universidade Técnica de Lisboa, Lisboa, PO.

SLATTER. D.H. Textbook of small animal surgery. 2.ed. Philadelphia: W.B. Saunders, 2003. p.25932605.

SROUGI, M.; DALL'OGLIO, M.; NESRALLAH, L.J. et al. Radical cystectomy with preservation of sexual function and urinary continence: description of a new technique. Surg. Tech., v.29, p.336-344, 2003.

YOSHIMURA K.; MAEKAWA S.; ICHIOKA K. et al. Tubeless cutaneous ureterostomy: the Toyoda method revised.J. Urol. v.165, p.785-788, 2001. 